This manuscript has been authored by UT-Battelle, LLC, under Contract No. DE-AC0500OR22725 with the U.S. Department of Energy. The United States Government retains and the publisher, by accepting the article for publication, acknowledges that the United States Government retains a non-exclusive, paid-up, irrevocable, worldwide license to publish or reproduce the published form of this manuscript, or allow others to do so, for United States Government purposes. The views expressed are those of the author and do not reflect the official policy or position of the Department of Defense or the U.S. Government.

\title{
Electrochemical Investigation of Stainless Steel Corrosion in a Proton Exchange Membrane Electrolyzer Cell
}

\author{
Jingke $\mathrm{Mo}^{1}$, Stuart M. Steen, $\mathrm{III}^{1}$, Feng-Yuan Zhang ${ }^{1, *}$ \\ Todd J. Toops ${ }^{2}$, Michael P. Brady ${ }^{2}$ and Johney B. Green Jr ${ }^{2}$ \\ ${ }^{1}$ Nanodynamics and High-Efficiency Lab for Propulsion and Power \\ Department of Mechanical, Aerospace \& Biomedical Engineering \\ UT Space Institute, University of Tennessee, Knoxville \\ 411 B H Goethert Pkwy
}

Tullahoma, TN 37388, USA

${ }^{2}$ Oak Ridge National Laboratory

1 Bethel Valley Rd

Oak Ridge, TN 37831, USA

* Corresponding author. Tel: +1-931-393-7428; Email address: fzhang@ utk.edu 


\begin{abstract}
The lack of a fundamental understanding of the corrosion mechanisms in the electrochemical environments of proton exchange membrane (PEM) electrolyzer and/or fuel cells (ECs/FCs) has seriously hindered the improvement of performance and efficiency of PEM EC/FC. In this study, a stainless steel mesh was purposely used as an anode gas diffusion layer that was intentionally operated with high positive potentials under harsh oxidative environments in a PEMEC to study the corrosion mechanism of metal migration. A significant amount of iron and nickel cations were determined to transport through the anode catalyst layer, the PEM and the cathode catalyst layer during the PEMEC operation. The formation/deposition of iron oxide and nickel oxide on the carbon paper gas diffusion layer at the cathode side is first revealed by both scanning electron microscope and x-ray diffraction. The results indicate the corrosion elements of iron and nickel are transported from anode to cathode through the catalyst-coated membrane, and deposited on carbon fibers as oxides. This phenomenon could also open a new corrosion-based processing approach to potentially fabricate multifunctional oxide structures on carbon fiber devices. This study has demonstrated a new accelerated test method for investigating the corrosion and durability of metallic materials as well.
\end{abstract}

Keywords: corrosion, membrane electrode assembly, proton exchange membrane electrolyzer/fuel cells, gas diffusion layer, x-ray diffraction, iron transport and deposition 


\section{Introduction}

Hydrogen, as a high energy and environment friendly fuel, has the potential to be a promising energy source in the near to intermediate future. An electrolyzer cell taking advantage of a proton exchange membrane (PEM) has attracted more attention for renewable energy storage and pure hydrogen/oxygen production due to their higher energy efficiency/density, faster charging/discharging, and a more compact design [1-4].

The proton exchange membrane electrolyzer cell (PEMEC) splits water into separate streams of hydrogen and oxygen by using electrical power. The integrations of water electrolysis and energy from sustainable resources, including solar, wind and biomass, are very attractive because of its high efficiency, renewable, and pure hydrogen production [5-10]. Once hydrogen is produced and stored, it can later provide a constant supply of electricity with a PEM fuel cell (PEMFC), which is a reverse device of the PEMEC. This regenerative system will allow renewable and hybrid energy systems to effectively provide reliable and multi-scale energy [11-14]. Compared to traditional technologies, both PEMECs and PEMFCs take advantage of proton exchange membranes as electrolytes that permit the transfer of protons with high efficiency. Their performance is highly dependent on properties of the membrane electrode assembly (MEA), including conductivity of the membrane, activation energy of the catalyst layers, and the conductivity and permeability of liquid/gas diffusion layers (LGDLs) [15-21]. PEMFC performance can also be affected by species concentration variations across and within the cells which can reflect changes in reactants and products distribution and transport, localized and possibly dynamic active-site blocking, and membrane degradation [22, 23]. 
Metallic LGDLs and bipolar plates have attracted attentions in both PEMECs and PEMFCs due to their high conductivity, rapid production, and low cost.[24-28] By taking advantage of novel designs and micro fabrications, a thin-film metallic LGDL with well-controllable pore morphologies and surface properties demonstrated excellent multi-functionalities and water managements [24, 29]. However, its durability has been challenged due to the aggressive electrochemical environment. In addition, while carbon paper is widely used as the LGDL in fuel cells, it is unsuitable in the anode side of PEMECs because it is easily corroded at the high positive potentials and extreme oxidative environments. Metallic LGDLs with higher corrosion resistance are one potential solution. Metal corrosion and ion poisoning on MEAs are critical issues especially for low-cost metals such as stainless steel. Current bipolar plate practically employs the use of more expensive metals such as titanium, and typically with precious metal coatings such as Pt, which significantly increase the cost [10]. It has been reported that metallic cations, especially iron cations, may contaminate the MEA and degrade the performance in PEMFCs [28, 30-33]. However, to our knowledge, there are few (if any) reports on the electrode corrosion and transport mechanisms/effects in a MEA, especially with metallic LGDLs.

In this study, a stainless steel mesh was purposely employed as the anode LGDL to develop an understanding of the metal ion migration and deactivation mechanism and identify alternative materials suitable for use in PEMEC. Scanning electron microscope (SEM) characterizations of both anode and cathode LGDLs before and after testing were performed to compare the extent of metal migration in the materials. X-ray diffraction (XRD) has been demonstrated to be an effective method that readily provides quantitative 
information about the phase-composition of solid material $[34,35]$. The LGDLs have also been analyzed by XRD for the identification of the form of the migrating metals. Migration of iron across the MEA resulting in the formation of iron oxide on the carbon paper gas diffusion layer at cathode side is observed, which to our knowledge is the first or among the first reports of this phenomenon for PEMEC.

\section{Experimental details}

In the PEMEC used in the present study, both end plates are made of aluminum. The anode current distributor with a parallel flow field is fabricated from a titanium plate, while the cathode current distributor is fabricated from copper and coated with nickel and chromium. The cathode flow field is also a parallel flow field that is fabricated from graphite. Both anode and cathode gaskets are made from PVC sheets. The cathode LGDL is Toray 090 carbon paper treated with 5\% PTFE. The anode LGDL is a type 316 stainless steel mesh (nominal composition of 316 is $16-18.5 \% \mathrm{Cr}, 10-14 \% \mathrm{Ni}, 2-3 \% \mathrm{Mo}$, $<2 \% \mathrm{Mn},<1 \% \mathrm{Si}$, all in weight \%). The catalyst-coated membrane (CCM) is Nafion 115 film with Ru/Ir oxides and Pt employed as anode and cathode catalysts with loadings of 3 $\mathrm{mg} / \mathrm{cm}^{2}$, respectively. Eight evenly distributed bolts assembled the cell to a torque of 40 lb-in. Teflon piping and fittings were used throughout the system. While the cathode tubing was merely intended to safely exhaust hydrogen gas, a diaphragm liquid pump from KNF Neuberger was used to circulate water at a constant volumetric flow rate of 40 $\mathrm{ml} / \mathrm{min}$ through the anode [21]. The electrolyzer with an active area of $5 \mathrm{~cm}^{2}$ was operated for 15 hours with an average operation voltage of $2.8 \mathrm{~V}$ at a current density of 1

$\mathrm{A} / \mathrm{cm}^{2}$ at room temperature. Before and after the water electrolyzer testing, the leak and 
crossover tests were performed with air. This evaluation produced identical results in the fresh and aged CCMs and no pinhole formation was found.

The morphological characteristics of the LGDLs were observed with a field emission SEM JEOL JSM-6320F with an accelerating voltage of $0.5-30 \mathrm{kV}$, a magnification of $500 \mathrm{x} \sim 650,000 \mathrm{x}$ and a 5-axis specimen mount. The EDS detector is an EDAX Octane plus Silicon Drift Detector that works in tandem with EDAX's TEAM EDS software analysis system. The system allows for high resolution mapping and highly accurate point analysis at fast speeds. SEM images were captured, processed, and analyzed by TEAM software.

The characterization of structure and identification of the phase were carried out by XRD with a Philips $X^{\prime}$ Pert materials research diffractometer $(45 \mathrm{kV}, 40 \mathrm{~mA})$, controlled by PANalytical's XRD software, in Bragg Brentano reflection geometry with $\mathrm{Cu} \mathrm{K \alpha}$ radiation $\left(\lambda=1.5418 \AA\right.$ ) and a $2 \theta$ scan from $20^{\circ}$ to $100^{\circ}$ (at $0.01^{\circ}$ per 5 second). The diffraction patterns are analyzed by software MDI Jade9.

\section{Results and discussion}

The experimental results include two major parts: SEM characterizations and XRD investigations of fresh and used LGDLs from both anode and cathode sides in PEMECs.

Figure 1 shows the SEM images of fresh and used stainless-steel LGDLs at anode side, which reveals extensive corrosion of the stainless steel mesh after 15 hours of room temperature operation at a cell voltage of $2.8 \mathrm{~V}$ and a current density of $1 \mathrm{~A} / \mathrm{cm}^{2}$ in PEMEC. As shown in Figure 1 (A), the surface of fresh stainless steel mesh is smooth, while the operated stainless steel shows a rough, corroded surface, which can be observed 
clearly in Figure 1 (B) and (C). The electrochemical reaction at anode side during PEMEC operation can be expressed as equation (1)

$$
2 \mathrm{H}_{2} \mathrm{O} \rightarrow 4 \mathrm{H}^{+}+\mathrm{O}_{2}+4 e^{-}
$$

The stainless steel at the anode side in the PEMEC experiences the high oxidative environment and high positive potentials. And the passive film is reported to be formed on the surface of stainless steel when the it is in the passive potential region, which is attributed to both reaction and diffusion mechanisms.[36] The growth of the oxide film is initially controlled by the oxidation reaction of iron and chrome elements. [37] Then, their diffusions becomes dominant in the barrier layer.[38] Passive films on stainless steels are heterogeneous and they have compositional and structural defects. The substance of the defects and the breakdown mechanism of passive films are still unclear. The reductive dissolution of the $\mathrm{Fe}_{2} \mathrm{O}_{3}$-component in passive films is considered to lead to passive film breakdown, which results in deeper corrosion in the substrate. $[39,40]$. The passive film adheres loosely on the surface and can be spalled from the substrate surface. Similar oxidative attacks have been reported for stainless steels in supercritical water [41]. As shown in Figure 1 (C), some of outer loose layer detaches from the substrate, the outer layer is brittle, and the inside smooth layer is exposed. Based on EDS analysis (Figure 1 (D)), the outer corroded layer is a Fe-base oxide, with the smooth inner layer consistent with 316 metal.

The SEM images of fresh and operated carbon paper of the cathode LGDL is shown in Figure 2. The SEM image Figure 2 (A) for fresh carbon indicates the surface of sample is smooth, and the carbon fibers can be observed clearly. The SEM image of Figure 2 (B) for used carbon paper shows the carbon fibers are fully covered by corrosion products, 
which is further examined in Figure 2 (C). The electrochemical reaction at cathode side results in hydrogen formation, which can be expressed as equation (2):

$$
4 H^{+}+4 e^{-} \rightarrow 2 H_{2}
$$

Since the environment in the cathode side is different from one at the anode side, it is not expected that the carbon paper would be corroded as badly as shown in the SEM images of Figure 2 (B) and (C). According to this phenomenon, an EDS scan was conducted, the results of which indicated that the elements of crystal deposited on the surface of carbon paper were $\mathrm{Fe}, \mathrm{Ni}$, and $\mathrm{O}$ rich, as shown in Figure 2 (D). It can be hypothesized that iron and nickel ions diffused from the anode side to the cathode side and deposited onto the surface of the carbon fibers. The ratio of the content of $\mathrm{Fe}$ and $\mathrm{Ni}$ was roughly 1.5:1.

The X-Ray Diffraction pattern comparisons of anode and cathode LGDLs before and after testing in PEMECs are shown in Figures 3 and 4, respectively. From the XRD pattern for the stainless steel mesh as shown in Figure 3 (A), the major phase at anode side LGDL fresh stainless steel 316 mesh is face-centered cubic austenite, although additional peaks consistent with deformation-induced alpha prime martensite were also observed (likely resulted from the mesh manufacturing process) [42]. After PEMEC operation, it can be observed that the peak intensity of $\alpha^{\prime}(110)$ became weaker, while the austenite peak (111) became stronger, according to the XRD pattern of the anode LGDL as shown in Figure 3 (B).

During PEMEC operation, only electrochemical reaction occurred inside the cell, which kept the stainless steel mesh in the harsh environment at the anode side of PEMECs, caused the formation of oxide layer on the surface of stainless steel mesh. In the water electrolysis process, the loosely oxide layer formed on the surface of anode LGDL 
stainless steel mesh $[37,41]$. Since the anode LGDL stainless steel mesh is exposed in the flow of DI water, the oxide layer can be easily detached from stainless steel substrate due to shear stress of the flow and dissolved into the flow water. This process results in the phenomena in Figure $1(\mathrm{C})$, rough outer iron oxide layer and smooth inner stainless steel substrate, which also has been verified by SEM results.

Figure 4 shows the XRD patterns for the cathode LGDL before and after testing, respectively. As shown in Figure 4 (A), the major phase in the cathode LGDL fresh carbon paper is graphite, which agrees well with reference [43]. After operation of the PEMEC, the XRD pattern for carbon paper, as show in Figure 4 (B), indicates iron oxide $\left(\mathrm{Fe}_{3} \mathrm{O}_{4}\right)$ and nickel oxide $(\mathrm{NiO})$ formation in the used carbon paper, which is absent in the fresh carbon paper. Those iron and nickel ions can only come from the anode LGDL, which is the sole portion of the PEMEC in which iron and nickel exists. In addition to the direct oxidation of iron, $\mathrm{Fe}$ and $\mathrm{Ni}$ cations can easily form into oxide in a wet environment [44]. This helps to explain why there is Fe oxide and Ni oxide on the surface of cathode LGDL carbon paper. This also indicates that the loose oxide layer of stainless steel detached from the stainless steel substrate, only some $\mathrm{Fe}$ oxide and $\mathrm{Ni}$ oxide dissolved into water with $\mathrm{PH}<7$, since $\mathrm{Cr}$ oxide is insoluble in water with $\mathrm{PH}<7$, the dissolved $\mathrm{Fe}$ and $\mathrm{Ni}$ ions transported from the anode LGDL stainless steel mesh to the cathode LGDL carbon paper through the catalyst-coated Nafion 115 membrane. The environment in the anode of the PEMEC is too aggressive for untreated stainless steel. The oxide films formed on 316 stainless steel exposed to anode high potential and extreme oxidative environment showed poor protection against corrosion. This baseline 
stainless steel sets a basis for the future evaluation of coatings and/or comparison with other materials like Ti, which is usually used for metal LGDL in PEMEC.

\section{Conclusion}

For a better understanding of the corrosion mechanisms and ion transitions in electrochemical devices, a stainless steel mesh was purposely used as anode gas diffusion layer and was operated in a PEMEC with intentionally higher positive potentials under harsher oxidative environments. Large amount of iron are found to transport from anode to cathode, through the anode catalyst layer, the proton exchange membrane and the cathode catalyst layer. The formation of iron oxide and nickel oxide on single carbon fibers of a carbon paper gas diffusion layer on the cathode side is observed by both scanning electron microscope and x-ray diffraction. A visual comparison between SEM images shows that high levels of oxidation occur in PEMECs at room temperature, especially at the anode side. The XRD pattern not only identifies the mechanism of oxidation on LGDLs, but also tracks the transportation pathways of corrosion from the anode to the cathode through the membrane along with SEM. The results indicate the corrosion elements of iron and nickel are transported from anode to cathode across through the catalyst-coated membrane, and deposited on carbon fibers. The test method and characterization have been demonstrated to be an effective approach to investigate corrosion mechanisms (transport and reformation) across MEAs in both quantitative and qualitative aspects. The addressed method could also open a new opportunity to fabricate multifunctional devices with single carbon fiber. In addition, this study has demonstrated a new accelerated test method, which can be easily for investigating the electrochemical corrosion and durability of various metallic materials. 


\section{Acknowledgements}

The authors acknowledge the support from U.S. Department of Energy's National Energy Technology Laboratory under Award DE-FE0011585. A portion of this research was performed with funding Grant \#DE-EE0000276 from the U.S. Department of Energy Fuel Cell Technologies Office, which is gratefully acknowledged. The authors also wish to express their appreciation to Douglas Warnberg, Dr. Bo Han, and Aaron Liu for their help. 


\section{References}

[1] Ayers KE, Capuano C, Anderson EB. Recent advances in cell cost and efficiency for PEM-based water electrolysis. ECS Transactions. 2012;41:15-22.

[2] Millet P, Mbemba N, Grigoriev SA, Fateev VN, Aukauloo A, Etievant C. Electrochemical performances of PEM water electrolysis cells and perspectives. Int J Hydrogen Energ. 2011;36:4134-42.

[3] Biyikoglu A. Review of proton exchange membrane fuel cell models. International Journal of Hydrogen Energy. 2005;30:1181-212.

[4] Carmo M, Fritz DL, Merge J, Stolten D. A comprehensive review on PEM water electrolysis. International Journal of Hydrogen Energy. 2013;38:4901-34.

[5] Grigoriev SA, Porembsky VI, Fateev VN. Pure hydrogen production by PEM electrolysis for hydrogen energy. International Journal of Hydrogen Energy. 2006;31:171-5.

[6] Marshall A, Borresen B, Hagen G, Tsypkin M, Tunold R. Hydrogen production by advanced proton exchange membrane (PEM) water electrolysers - Reduced energy consumption by improved electrocatalysis. Energy. 2007;32:431-6.

[7] Turner JA. Sustainable hydrogen production. Science. 2004;305:972-4.

[8] Wang H, Deutsch T, Turner JA. Direct water splitting under visible light with nanostructured hematite and WO3 photoanodes and a GaInP2 photocathode. J Electrochem Soc. 2008;155:F91F6.

[9] Han B, Steen SM, Mo J, Zhang F-Y. Electrochemical performance modeling of a proton exchange membrane electrolyzer cell for hydrogen energy. Int J Hydrogen Energ. 2015 (in press); doi:10.1016/j.ijhydene.2015.03.164.

[10] Barbir F. PEM electrolysis for production of hydrogen from renewable energy sources. Sol Energy. 2005;78:661-9.

[11] Fall J, Humphreys D, Guo SM. Design and Testing of a Unitized Regenerative Fuel Cell. J Fuel Cell Sci Tech. 2009;6.

[12] Strand A, Weydahl H. Regenerative Fuel Cell Systems for Satellites. 8th European Space Power Conference2008.

[13] Shapiro D, Duffy J, Kimble M, Pien M. Solar-powered regenerative PEM electrolyzer/fuel cell system. Sol Energy. 2005;79:544-50.

[14] Muradov N. Emission-free fuel reformers for mobile and portable fuel cell applications. J Power Sources. 2003;118:320-4.

[15] Song S, Zhang H, Ma X, Shao Z, Baker RT, Yi B. Electrochemical investigation of electrocatalysts for the oxygen evolution reaction in PEM water electrolyzers. International Journal of Hydrogen Energy. 2008;33:4955-61.

[16] Ma LR, Sui S, Zhai YC. Investigations on high performance proton exchange membrane water electrolyzer. International Journal of Hydrogen Energy. 2009;34:678-84.

[17] Song SD, Zhang HM, Ma XP, Shao ZG, Zhang YN, Yi BL. Bifunctional oxygen electrode with corrosion-resistive gas diffusion layer for unitized regenerative fuel cell. Electrochem Commun. 2006;8:399-405.

[18] Liu H, Yi BL, Hou M, Wu JF, Hou ZJ, Zhang HM. Composite electrode for unitized regenerative proton exchange membrane fuel cell with improved cycle life. Electrochem Solid St. 2004;7:A56A9.

[19] Xu W, Scott K, Basu S. Performance of a high temperature polymer electrolyte membrane water electrolyser. J Power Sources. 2011;196:8918-24.

[20] Toops TJ, Brady MP, Zhang F-Y, Meyer HM, Ayers K, Roemer A, et al. Evaluation of Nitrided Titanium separator plates for proton exchange membrane electrolyzer cells. J Power Sources. 2014.

[21] Steen SM, Zhang F-Y. In-situ and Ex-situ Characterizations of Electrode Interfaces in Energy Storage Electrolyzers. ECS Transactions. 2014;59:95-102.

[22] Partridge W, Toops TJ, Green J, Armstrong TR. Intra-fuel cell stack measurements of transient concentration distributions. J Power Sources. 2006;160:454-61.

[23] Peighambardoust SJ, Rowshanzamir S, Amjadi M. Review of the proton exchange membranes for fuel cell applications. International Journal of Hydrogen Energy. 2010;35:9349-84. 
[24] Zhang F-Y, Advani SG, Prasad AK. Performance of a metallic gas diffusion layer for PEM fuel cells. J Power Sources. 2008;176:293-8.

[25] Matsuura T, Kato M, Hori M. Study on metallic bipolar plate for proton exchange membrane fuel cell. J Power Sources. 2006;161:74-8.

[26] Arisetty S, Prasad AK, Advani SG. Metal foams as flow field and gas diffusion layer in direct methanol fuel cells. J Power Sources. 2007;165:49-57.

[27] Tawfik H, Hung Y, Mahajan D. Metal bipolar plates for PEM fuel cell—a review. J Power Sources. 2007;163:755-67.

[28] Wang H, Turner JA. Reviewing Metallic PEMFC Bipolar Plates. Fuel Cells. 2010;10:510-9.

[29] Zhang F-Y, Prasad AK, Advani SG. Investigation of a copper etching technique to fabricate metallic gas diffusion media. J Micromech Microeng. 2006;16:N23.

[30] Wang HL, Turner JA. The influence of metal ions on the conductivity of Nafion 112 in polymer electrolyte membrane fuel cell. J Power Sources. 2008;183:576-80.

[31] Brady MP, Wang H, Turner JA, Meyer HM, More KL, Tortorelli PF, et al. Pre-oxidized and nitrided stainless steel alloy foil for proton exchange membrane fuel cell bipolar plates: Part 1. Corrosion, interfacial contact resistance, and surface structure. J Power Sources. 2010;195:5610-8.

[32] Joseph S, McClure JC, Chianelli R, Pich P, Sebastian PJ. Conducting polymer-coated stainless steel bipolar plates for proton exchange membrane fuel cells (PEMFC). Int J Hydrogen Energ. 2005;30:1339-44.

[33] Kumar A, Ricketts M, Hirano S. Ex situ evaluation of nanometer range gold coating on stainless steel substrate for automotive polymer electrolyte membrane fuel cell bipolar plate. J Power Sources. 2010;195:1401-7.

[34] Zhang F-Y, Advani SG, Prasad AK. Advanced High Resolution Characterization Techniques for Degradation Studies in Fuel Cells. Polymer Electrolyte Fuel Cell Degradation. 2011:365.

[35] Zhang FY, Advani SG, Prasad AK, Beebe TP, Khalifa ZS, Shah SI. Investigation of freeze/thaw effects on catalyst layer degradation in fuel cells with XPS and XRD. Fuel Cell Seminar. 2009.

[36] Fredriksson W, Malmgren S, Gustafsson T, Gorgoi M, Edström K. Full depth profile of passive films on 316L stainless steel based on high resolution HAXPES in combination with ARXPS. Applied Surface Science. 2012;258:5790-7.

[37] Gao X, Wu X, Zhang Z, Guan H, Han E-h. Characterization of oxide films grown on 316L stainless steel exposed to $\mathrm{H} 2 \mathrm{O}$ 2-containing supercritical water. The Journal of supercritical fluids. 2007;42:157-63.

[38] Zhang J, Li N, Chen Y, Rusanov A. Corrosion behaviors of US steels in flowing lead-bismuth eutectic (LBE). Journal of Nuclear Materials. 2005;336:1-10.

[39] Son M, Akao N, Hara N, Sugimoto K. Electrochemical and Corrosion Properties of $\mathrm{Fe} 2 \mathrm{O} 3 \mathrm{Cr} 2 \mathrm{O} 3 \mathrm{MoO} 2$ Artificial Passivation Films in $\mathrm{HCl}$ Solutions. J Electrochem Soc. 2001;148:B43-B50.

[40] Sugimoto K, Son M, Ohya Y, Akao N, Hara N. Corrosion Science-A Retrospective and Current Status in Honor of Robert P. Frankenthal, Electrochemical Society Proceedings.2002:13.

[41] Luo X, Tang R, Long CS, Miao Z, Peng Q, Li C. Corrosion behavior of austenitic and ferritic steels in supercritical water. Nucl Eng Technol. 2008;40:147-54.

[42] Solomon N, Solomon I. Deformation induced martensite in AISI 316 stainless steel. Rev Metal Madrid. 2010;46:121-8.

[43] Li ZQ, Lu CJ, Xia ZP, Zhou Y, Luo Z. X-ray diffraction patterns of graphite and turbostratic carbon. Carbon. 2007;45:1686-95.

[44] Cui HT, Liu Y, Ren WZ. Structure switch between alpha-Fe2O3, gamma-Fe2O3 and Fe3O4 during the large scale and low temperature sol-gel synthesis of nearly monodispersed iron oxide nanoparticles. Adv Powder Technol. 2013;24:93-7. 


\section{Figures captions}

Figure 1. SEM images of anode LGDL stainless steel mesh, (A) fresh sample; (B) used sample; (C) Close-up of (B); (D) EDS results.

Figure 2. SEM images of cathode LGDL carbon paper, (A) fresh sample; (B) used sample; (C) Close-up of (B); (D) EDS results.

Figure 3. XRD patterns of anode LGDL, (A) fresh sample; (B) used sample.

Figure 4. XRD patterns of cathode LGDL, (A) fresh sample; (B) used sample. 

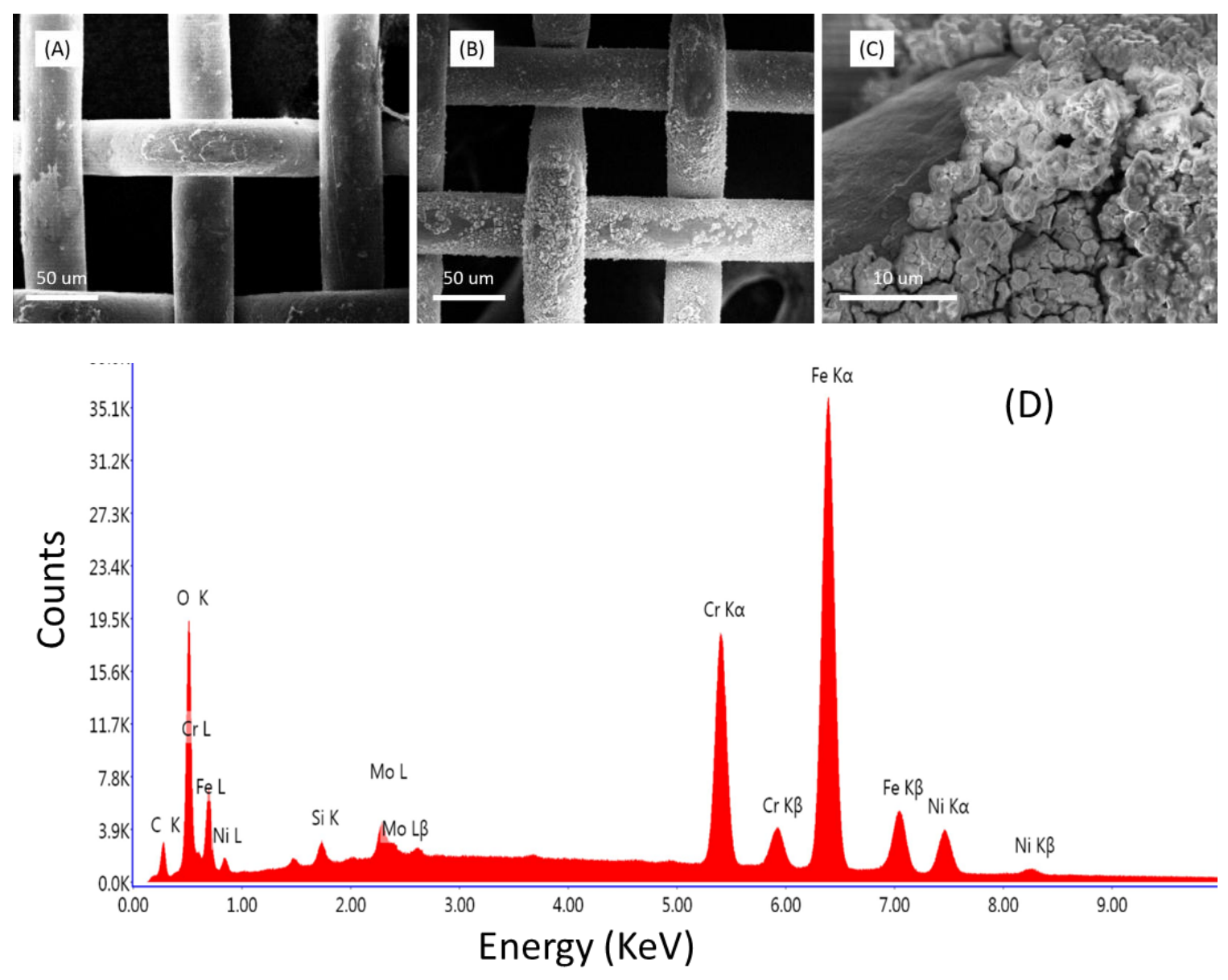

Figure 1 

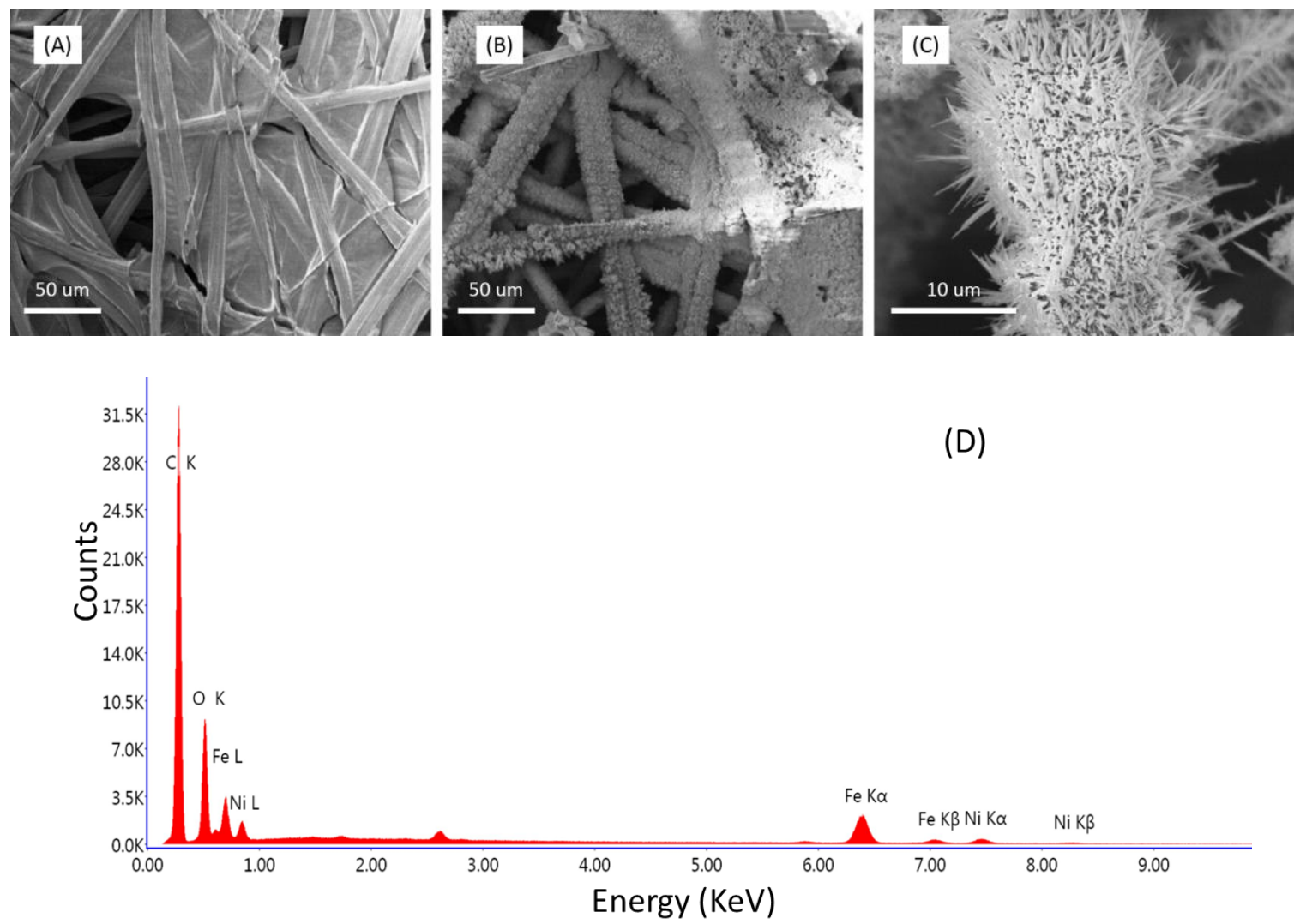

Figure 2 


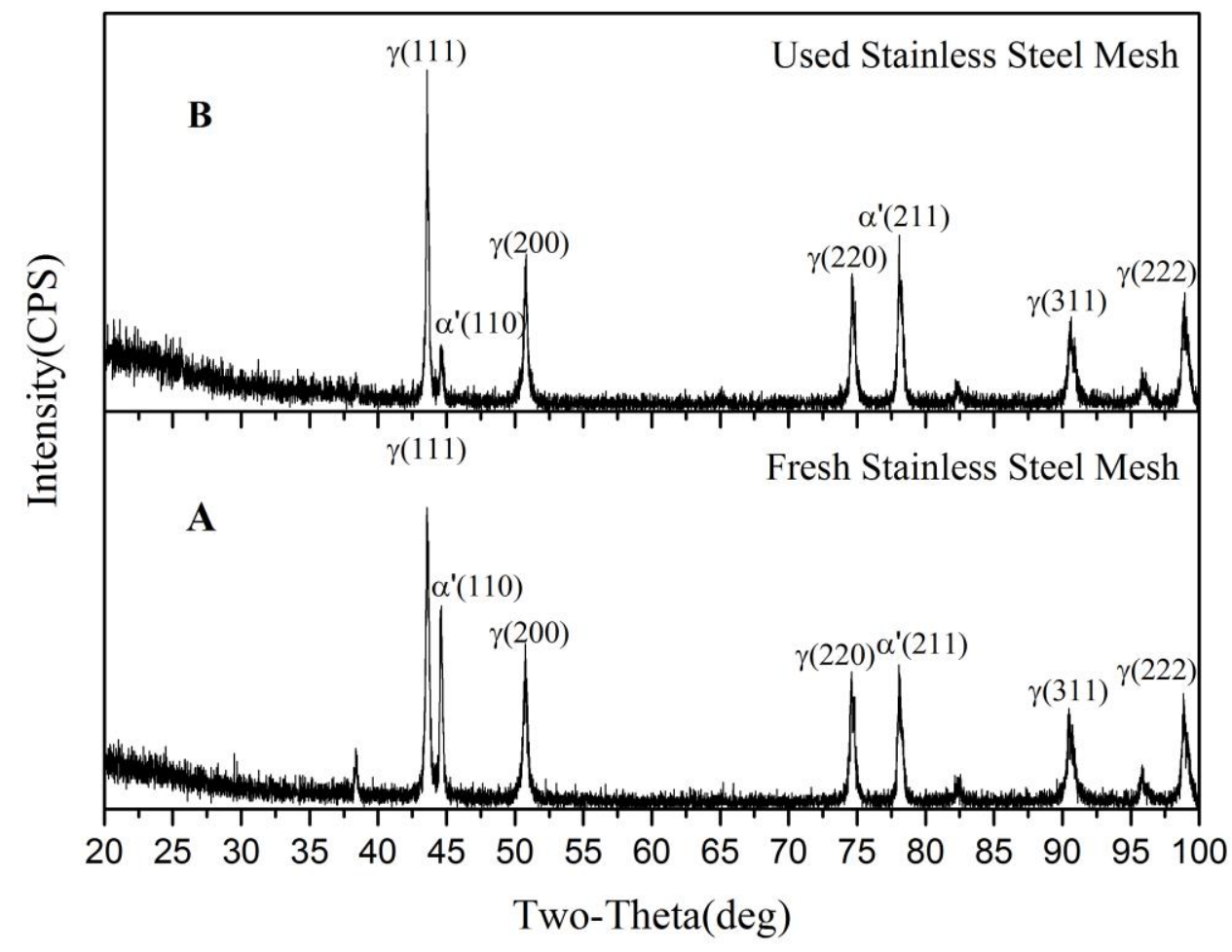

Figure 3 


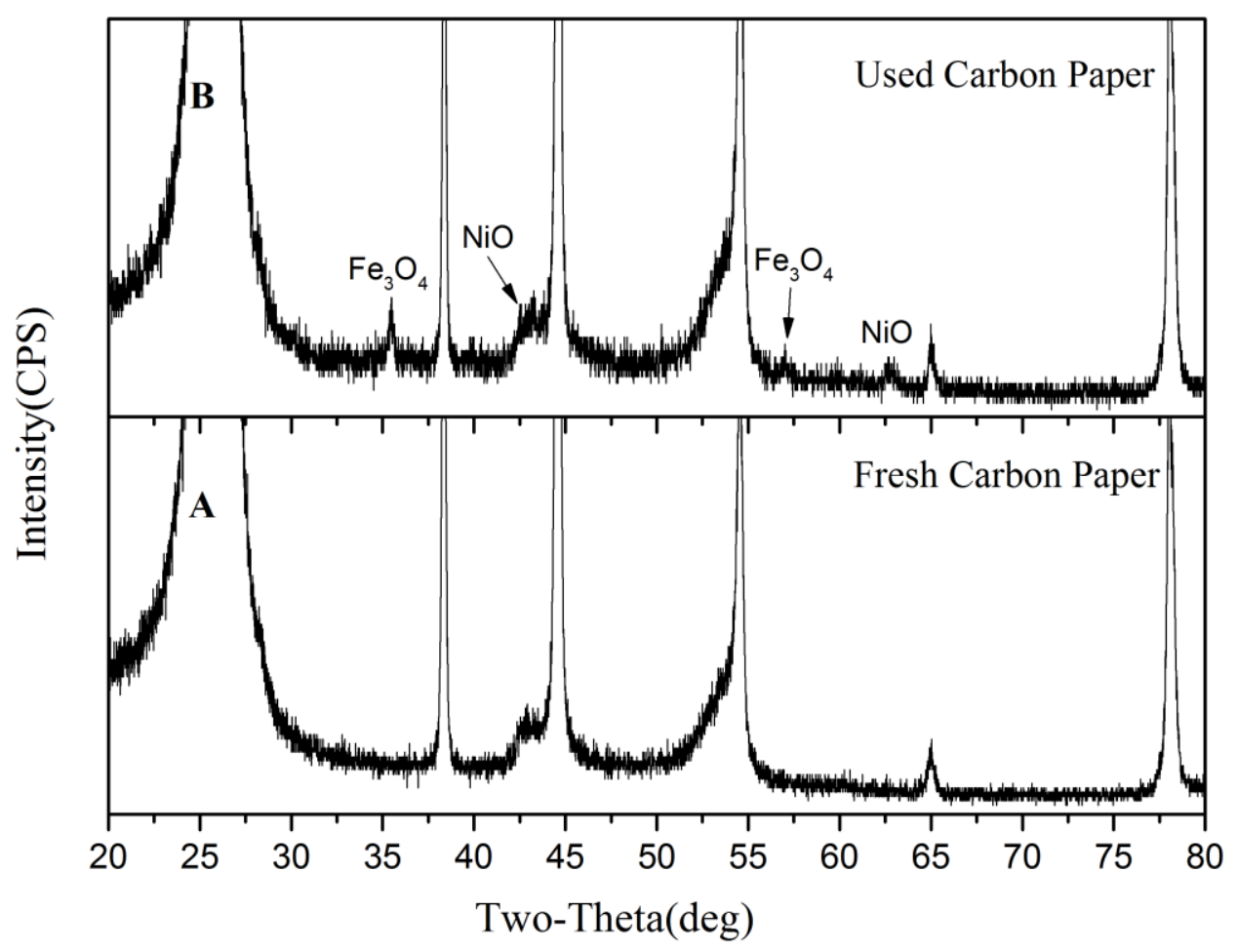

Figure 4 